\title{
An Analysis of the Internationalization of Chinese Excellent Traditional Culture
}

\author{
Wen-miao GAO \\ Zhejiang University; Communication University of Zhejiang \\ Zhejiang, Hangzhou, China \\ 1241440155@qq.com
}

\begin{abstract}
Chinese excellent traditional culture, as the spiritual wealth and wisdom of the Chinese nation, is an important guarantee for national rejuvenation and country's prosperity, and it's the essence of human civilization and world culture. Carrying forward and inheriting Chinese excellent traditional culture is not only the mission of social development, but also the inevitable requirement of historical development, and the basic trend of global development. The internationalization of Chinese excellent traditional culture is an important way to carry forward and inherit Chinese excellent traditional culture. It not only manifests the conscious responsibility of the country and the nation, but also embodies the long-term vision of the times and the world. This article mainly analyzes the significance, philosophy and ways of the internationalization of Chinese excellent traditional culture.
\end{abstract}

Keywords-Chinese excellent traditional culture; Internationalization; Cultural communication; International communication

\section{INTRODUCTION}

The excellent traditional Chinese culture contains excellent ideas, rich knowledge, diverse skills and a large number of objects. It is the spiritual wealth and wisdom of the Chinese nation. It is an important guarantee for the rejuvenation of the nation and the prosperity of the country. It is also the essence of human civilization and the world culture. The Chinese excellent traditional culture needs to carry forward and inherit, which is not only the time mission of the social development, but also the inevitable requirement of the historical development, and it is also the basic trend of the global development. The internationalization of Chinese excellent traditional culture is an important way to carry forward and inherit Chinese excellent traditional culture. It is also an important way to promote the innovative development of Chinese excellent traditional culture. It has great practical significance to make Chinese excellent traditional culture go abroad and face the world. The following mainly focuses on the significance, philosophy and ways of the internationalization of Chinese excellent traditional culture. The significance of internationalization mainly covers the sharing of human civilization, the dissemination of ideological discourse and the promotion of cultural influence, and the international philosophy mainly embodies the three inevitability of universal connection, the development of the

${ }^{1}$ This article is the periodical result of the sixty-third batch of projects funded by the post doctoral Science Foundation of China: "the study of excellent traditional cultural education of China in the new era"

(2018M632495) world and the development of history. The main ways of internationalization include promoting international projects, building communication platforms and promoting nongovernmental communications.

\section{THE INTERNATIONAL SIGNIFICANCE OF CHINESE EXCELLENT TRADITIONAL CULTURE}

The internationalization of Chinese excellent traditional culture is the international communication of the collective wisdom of the Chinese nation, the international sharing of the Chinese civilization, and the international popularization of the excellent culture. It has great significance in the times, and will help to share the human civilization, disseminate the true meaning of thought and enhance the influence of the culture. The internationalization of Chinese excellent traditional culture can play an important role in human, country, nation, society and cultural communication and integration.

\section{A. It benefits to share human civilization}

Chinese excellent traditional culture is a concentrated manifestation of the Chinese culture for 5000 years, and it is also a fruitful achievement of human civilization. As an important part of human civilization, Chinese excellent traditional culture is both material and spiritual. It belongs to China and also the whole world. "Chinese civilization is one of the most important sources of world civilization, and it is the most coherent civilization that has been inherited and developed." [1] The internationalization of Chinese excellent traditional culture is mainly to make Chinese excellent traditional culture go abroad, to be acquainted with all countries and to achieve the state that all people sharing of Chinese excellent traditional culture, thus contributing to the sharing of human civilization and feeling the essence of the Chinese traditional culture in depth.

\section{B. It helps to disseminate the true meaning of thought}

The Chinese traditional culture contains rich thoughts and a certain value orientation. "The value orientation of Chinese traditional culture is life, mind and human nature." [2] All these are embodied in the core ideas, the Chinese traditional virtues and the Chinese humanistic spirit. And the content of thought needs to be expressed through certain words. The internationalization of Chinese excellent traditional culture is essentially a kind of communication behavior. Most 
importantly is the international communication of cultural thought and discourse, of which purpose is to make the Chinese excellent traditional culture spread in the world, thus helping to show the true meaning of the thought in the culture.

\section{It contributes to enhance the influence of culture}

Chinese excellent traditional culture, as an important source of socialist culture with Chinese characteristics, is an important manifestation of cultural soft power and comprehensive national strength. On the one hand, the internationalization of Chinese excellent traditional culture benefits from the continuous growth of the comprehensive national strength. On the other hand, it comes from the culture self-confidence. "Cultural communication and cultural integration are important parts of cultural development. It is difficult to develop culture without absorbing foreign cultures."[3] Making Chinese excellent traditional culture going abroad is not only a kind of interaction and communication of culture, but also a kind of external display of culture, which will help to further promote the world influence of Chinese culture.

\section{THE INTERNATIONAL PHILOSOPHY OF CHINESE EXCELLENT TRADITIONAL CULTURE}

The internationalization of Chinese excellent traditional culture is an inevitable choice for the development of the times. It is also an inevitable trend of spiritual prosperity. It has an inherent philosophical basis and logical inevitability, mainly covering the inevitability of the universal connection, the inevitability of the development of the world and the inevitability of the progress of history, meanwhile the emphasis on the dimensions of the three aspects are different. The inevitability of universal connection is mainly based on the dimension of the vertical and horizontal relations between things and objects. The inevitability of the development of the world is mainly based on the horizontal dimension of space, and the inevitability of the progress of history is mainly based on the longitudinal dimension of the time.

\section{A. The inevitability of universal connection}

Things are universally connected, and connections are universal. Whether it happens between different countries, between different people, or between different things, connection is the inherent inevitability. And its reflection in culture aspect is the cultural communication, which is the inner philosophical basis of the internationalization of Chinese excellent traditional culture's implementation. There are certain differences among different countries from cultural background, cultural basic and cultural gene, thus there is a gap between different cultures. It requires the interaction and intercommunication between cultures, so as to achieve a different state of harmony. The process of internationalization of Chinese excellent traditional culture is also a process of cultural intercommunication. Its inherent essence lies in the similarities between cultures.

\section{B. The inevitability of world development}

Things are always in the process of continuous development and change. From the point of view of space, the world will increasingly form a close community. People and people, people and states, people and the world are organic united, and always in the development and change. The development of the world needs to be based on the common development of all countries, and the key to common development is to have a common basis for discourse, in which cultural discourse is a very important ideological basis. The internationalization of Chinese excellent traditional culture is the inevitable requirement of the development of the world. It is mainly to make the countries form the common base of discourse and form the interlinked cultural thought.

\section{The inevitability of historical progress}

In the progress of society, the development of the times and the moving forward of history, it is mainly reflected in the continuous evolution of the social form and the continuous change of the cultural form. From the dimension of time, history is always moving forward in the continuous zigzags. The communication and integration of cultures is an inevitable choice for historical progress. The internationalization of Chinese excellent traditional culture is an important way of cultural communication. It is an important way to promote cultural communication in all countries, especially the respect, identification and absorption of Chinese excellent traditional culture. 


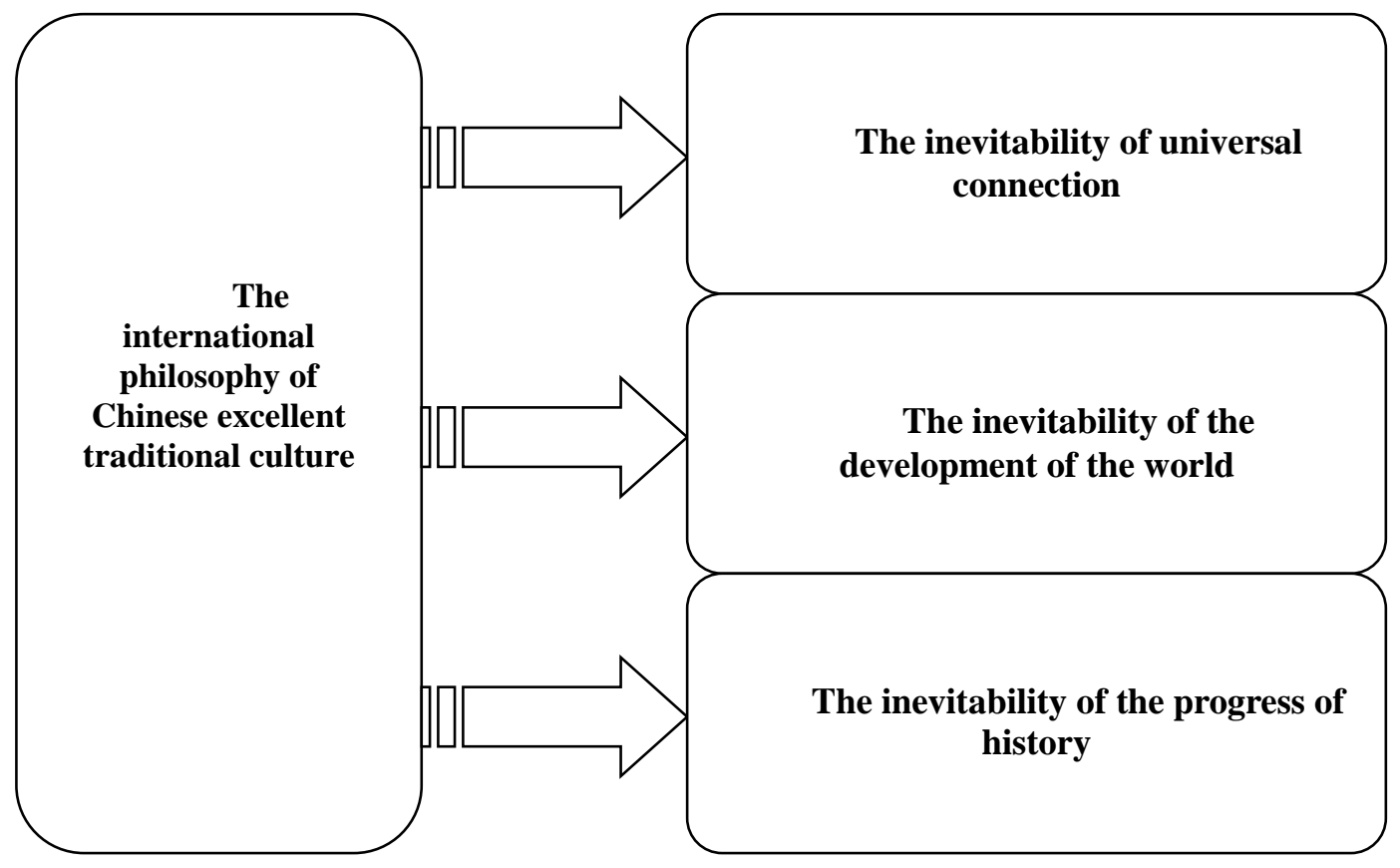

Fig. 1 The international philosophy of Chinese excellent traditional culture

\section{THE WAY OF THE INTERNATIONALIZATION OF CHINESE EXCELLENT TRADITIONAL CULTURAL}

To promote the internationalization of Chinese excellent traditional culture progressively, the key to ensure the effectiveness of internationalization is up to the way adopted. The way to internationalize the Chinese excellent traditional culture will need the government leading, the participation of the whole people and the linkage of the online and offline activities. In details, it could take the way to promote international projects, building network platforms and strengthening non-governmental communications among them. The promotion of international projects is to gradually form a situation of cultural communication and integration through point by point. The actively building a network platform is to gradually form a situation of cultural communication and exchange by online stimulating offline. The strengthening of non-governmental communications will gradually form a situation that non-governmental and official communication are mutual complemented and re-unforced with each other.

\section{A. Promoting international projects}

The internationalization of Chinese excellent traditional culture can be carried out through the form of international cooperation projects. It can carry out thematic cooperation or comprehensive cooperation around the theme of culture, and actively enrich the forms of communication between countries and countries. At present, the Belt and one Road initiatives is being promoted in an all-round way in our country, and the Confucius Institute in being opened different countries in the world. To a certain extent, they will also help the interaction and communication of Chinese excellent traditional culture to the outside world. The promotion of international projects is the leading behavior based on the government, and focus on the cultural communication and it's carrier between countries and countries, aiming at forming a cultural resonance and intercommunication, thus achieving the international goal of Chinese excellent traditional culture.

\section{B. Building network platforms}

Relying on the increasingly mature and developed network technology, the international interconnection platform is set up in an all-round way, the superiority of network communication is fully played, and the international communication and promotion of culture are constantly strengthened. The construction of network interconnection platform requires the network agreement among countries. And it also needs the technological match-up, support and protection. The international cooperation projects of Chinese excellent traditional culture can be promoted through online and offline channels, in which the online channels are mainly the way of international network interconnection. Building the network platform is an important way to promote the internationalization of Chinese excellent traditional culture. It is the main way to enhance the external influence and dissemination of Chinese excellent traditional culture. It is the external guarantee to enhance the effectiveness of the internationalization of Chinese excellent traditional culture.

\section{Strengthening non-governmental communications}

It will also help to promote the recognition and acceptance of different cultures. The internationalization of Chinese excellent traditional culture is mainly to tell good Chinese stories, spread Chinese voice, and the interpretation of Chinese culture, it can enable Chinese excellent traditional culture to expose to millions of people from all over the world. From the way, it can be realized through official and non-governmental communications. There are various forms of non-governmental 
communications, which can mainly include forums, conversations, studies, visits and so on. Non-governmental communication is a useful supplement to official communication, and will play an increasingly important role in cultural communications. The non-governmental communication is aimed at promoting the mutual recognition of the people of all countries, especially the mutual understanding of the culture. Thus, it will gradually make the Chinese excellent traditional culture to show its own inner beauty, so that all the people of the world can truly appreciate the essence of the Chinese excellent traditional culture from the inner recognition and acceptance of the traditional Chinese culture excellence.

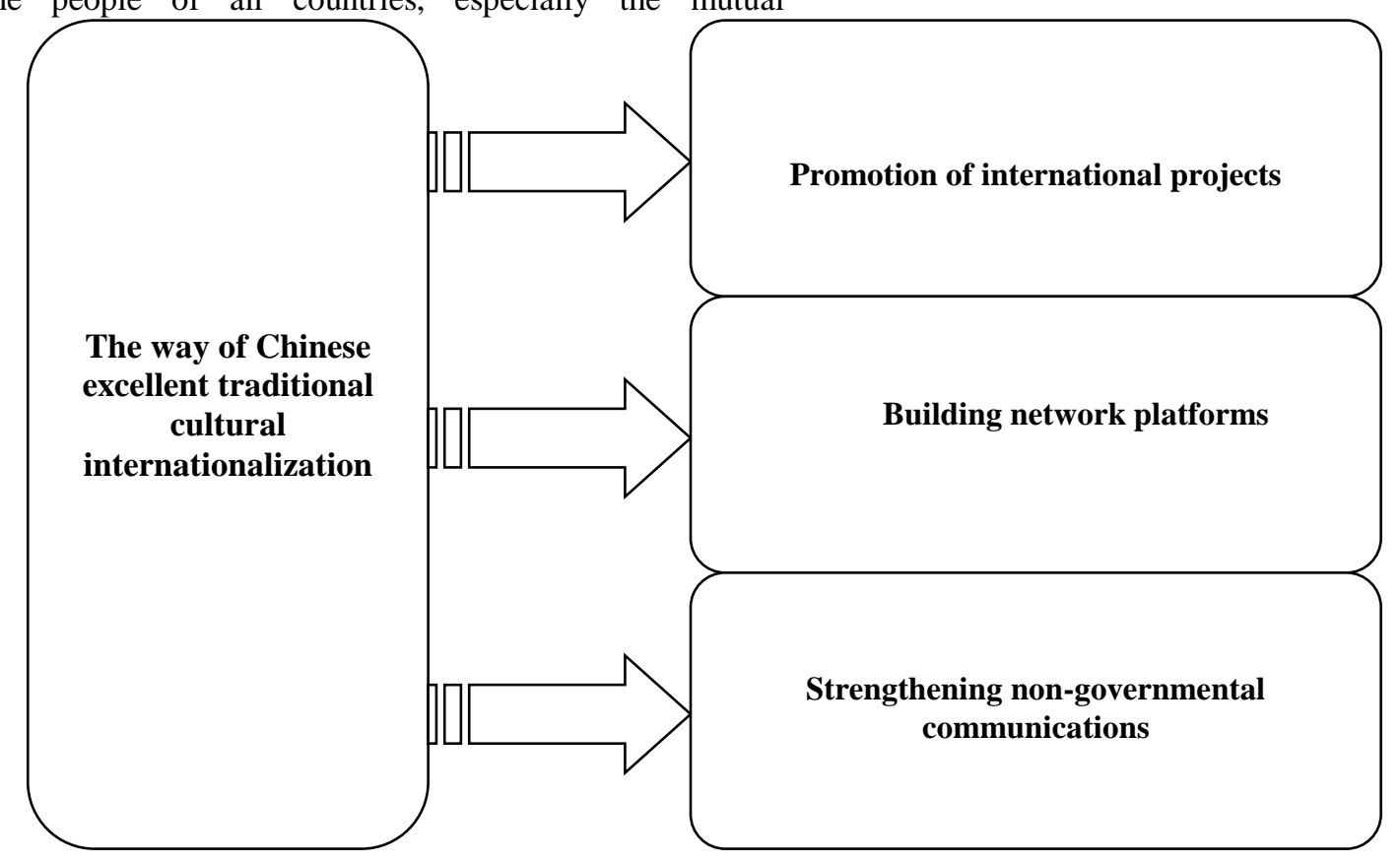

Fig. 2 The way of Chinese excellent traditional cultural internationalization

\section{SUMMARY}

In conclusion, the internationalization of Chinese excellent traditional culture which has an inherent logical philosophy, is not only the inevitable choice and inevitable trend of the development of the times, but also an important way to carry forward and inherit the excellent traditional culture of China. Based on the inevitability of universal connection, the inevitability of the development of the world and the inevitability of the progress of history, the internationalization of Chinese excellent traditional culture has the logical philosophy of inherent inevitability. The internationalization of Chinese excellent traditional culture is of great significance. It can help to share the human civilization, disseminate the true meaning of the thought and enhance the influence of the culture. We could promote the internationalization of Chinese excellent traditional culture by promoting international projects, building network platforms and strengthening nongovernmental communications. In this way, the content and form beauty of the Chinese excellent traditional culture are highlighted, and the Chinese traditional culture is finally accepted and internalized by the people from all of the world.

\section{REFERENCES}

[1] Dai-nian. Zhang, Chinese culture spirit, Beijing: Peking University press, March 2015 1st ed, pp. 183.

[2] Xiao-yue. Xu, Ming-sheng. Wang, Famous scholar on traditional culture and morality, Nanjing University press, October 2017 1st ed, pp. 3.

[3] Rong-ming. Zhang, Chinese Sinology, commercial press, April 2014 1st ed, pp. 142 